\title{
PATERNALISMO, ESCLAVITUD, DERECHOS DE PROPIEDAD Y MATRIMONIO EN JOHN STUART MILL*
}

Mauricio Pérez Salazar

* DOI: https://doi.org/10.18601/01245996.v21n40.06. E1 autor agradece los comentarios de Homero Cuevas a una versión antigua de este artículo. Recepción: 11-09-2018, modificación final: 25-09-2018, aceptación: 30-102018. Sugerencia de citación: Pérez S., M. (2019). Paternalismo, esclavitud, derechos de propiedad y matrimonio en John Stuart Mill. Revista de Economía Institucional, 21(40), 163-183.

a A. B. en Economía Política, Princeton University. Profesor de la Facultad de Economía, Universidad Externado de Colombia, Bogotá, [mauricio.perez@ uexternado.edu.co], [https://orcid.org/0000-0002-6421-6543]. 


\section{Paternalismo, esclavitud, derechos de propiedad y matrimonio en John Stuart Mill}

Resumen. ¿Hasta qué punto debe llegar la libertad individual? John Stuart Mill, defensor de este valor, sostuvo que no se podía ser libre para no ser libre y postuló como caso extremo el ejemplo de alguien que se vende voluntariamente como esclavo. Ese ejemplo ha generado un vivo debate sobre la consistencia de sus posiciones. Este artículo reseña ese debate y procura precisar los puntos de vista de Mill desde varias líneas convergentes: el paternalismo, la esclavitud, los derechos de propiedad y la intervención del Estado en la economía, y el matrimonio y la igualdad de género.

Palabras clave: John Stuart Mill, libertad, paternalismo, esclavitud, derechos de propiedad, matrimonio, igualdad de género; JEL: A13, B12, B31, K11, K38.

Paternalism, slavery, property rights and marriage in John Stuart Mill

Abstract. What are the limits of individual freedom? John Stuart Mill, who was an ardent advocate of liberty as a fundamental value, held that one could not freely choose to be unfree, and posited the extreme example of a person who willingly sells himself as a slave. His example has generated a debate about the consistency of Mill's positions. This article reviews this debate and tries to clarify his point of view using several convergent lines of argument: paternalism, slavery, the definition of property rights and public intervention of the state in markets, and marriage and gender equality.

Keywords: John Stuart Mill, liberty, paternalism, slavery, property rights, marriage, gender equality; JEL: A13, B12, B31, K11, K38.

\section{Paternalismo, escravidão, direitos de propriedade e casamento em John Stuart Mill}

Resumo. Até que ponto a liberdade individual deve chegar? John Stuart Mill, defensor desse valor, argumentou que não se podia ser livre para não ser livre e apresentou como caso extremo o exemplo de alguém que se vende voluntariamente como escravo. Esse exemplo gerou um debate animado sobre a consistência de suas posições. Este artigo analisa esse debate e procura esclarecer as visões de Mill a partir de várias linhas convergentes: o paternalismo, a escravidão, os direitos de propriedade e a intervenção estatal na economia, e o casamento e a igualdade de gênero

Palavras-chaves: John Stuart Mill, liberdade, paternalismo, escravidão, direitos de propriedade, casamento, igualdade de gênero; JEL: A13, B12, B31, K11, K38. 


\section{INTRODUCCIÓN: LOS TÉRMINOS DE UN DEBATE}

G $\mathrm{n}$ una controversial sentencia que determinó la despenalización Cde la dosis personal de estupefacientes, la Corte Constitucional de Colombia tuvo como eje de razonamiento la siguiente proposición sobre los límites de la autoridad del Estado y de la libertad individual:

[Si] asumimos que no se trata de un Estado omnímodo, con pretensiones de injerencia en las más íntimas decisiones del sujeto destinatario, sino de un Estado paternalista y protector de sus súbditos, que conoce mejor que éstos lo que conviene a sus intereses y hace entonces obligatorio lo que para una persona libre sería opcional, por esa vía benévola se llega al mismo resultado inadmisible: la negación de la libertad individual, en aquel ámbito que no interfiere con la esfera de la libertad ajena (C-221/1994).

E1 enfrentamiento de distintas concepciones sobre los linderos entre libertad individual y autoridad pública es recurrente en el pensamiento social de Occidente y se refleja en el contraste entre visiones paternalistas y antipaternalistas. Este artículo explora un momento de esa controversia, la respuesta del economista y filósofo político inglés John Stuart Mill a la paradójica pregunta de si la libertad individual abarca el derecho a renunciar a ella. Con ese objeto, examina la cuestión desde varias perspectivas: la esclavitud, los derechos de propiedad, el matrimonio y la igualdad de género.

$¿$ Fue inconsistente Mill al defender la libertad individual mientras que admitía algunas excepciones de carácter paternalista?

La definición de Gerald Dworkin (aunque sea una de muchas posibles) es un buen marco de referencia para discutir el paternalismo:

$\mathrm{X}$ obra de manera paternalista con respecto de $\mathrm{Y}$ haciendo (u omitiendo) $\mathrm{Z}$ :

1. Z (o su omisión) interfiere con la libertad o autonomía de Y.

2. $\mathrm{X}$ lo hace sin el consentimiento de Y.

3. $\mathrm{X}$ lo hace porque $\mathrm{Z}$ mejorará el bienestar de $\mathrm{Y}$ (esto incluye impedir que su bienestar se deteriore) o de alguna manera promoverá los intereses y valores de Y (Dworkin, 2017).

Según Dworkin, hay muchas variedades de paternalismo. La distinción más relevante es la que existe entre paternalismo fuerte, que implica interferencia estatal o social en los fines de los individuos, y débil o suave, que afecta la elección de los medios que ellos eligen. No hay antipaternalismo absoluto, según la definición antes citada, pues esa interferencia se puede justificar por conductas de Y que tienen efectos negativos (o externalidades) para terceros. Tampoco hay cuando se trata de niños u otras personas que carecen del uso de razón. 
Respecto a ellos, y ese es el significado literal del paternalismo, prima el deber de cuidado, tutela y protección de las personas responsables, o en su defecto del Estado, sobre el respeto de la libertad individual.

El capítulo final de Sobre la libertad de Mill se titula "A plicaciones" e incluye varios ejemplos de los límites de la libertad individual. Uno de estos es "el principio de [que la] libertad no puede requerir que una persona sea libre para no ser libre", por cuanto

en este y en la mayoría de los demás países civilizados un compromiso mediante el cual una persona se vende, o permite que se le venda, como esclava sería nulo e inválido; y no sería susceptible de hacerse cumplir por la ley ni por la opinión pública. El motivo de limitar así su capacidad de disponer de su propia suerte en la vida es evidente y se ve claramente en ese caso extremo. La razón de no interferir con los actos voluntarios de una persona (a menos que sea para proteger a terceros) es el respeto de su libertad. Su decisión voluntaria es evidencia de que lo que elige es deseable, o por lo menos soportable para ella; y la mejor manera de lograr su beneficio es permitir que escoja su propia manera de buscarlo. Pero al venderse como esclava abdica a su libertad; renuncia a cualquier uso futuro de ella, más allá de ese acto singular (CW, XVIII, p. 299).

Este texto ha generado un vivo debate sobre cuán paternalista era Mill y sobre la coherencia del mismo con otros aspectos de su pensamiento.

La definición de Dworkin se refiere únicamente a la interferencia con conductas que solo afectan al actor (self-regarding) y que no tienen efectos para otras personas. En el ejemplo de Mill, X (la sociedad) sería paternalista si, y solo si, impide que $Y$ se convierta voluntariamente en esclavo, por razones exclusivamente relacionadas con el bienestar de Y. Dworkin sugirió que Mill complementa el argumento utilitario usual -las consecuencias de elegir ser esclavo, así sea en forma voluntaria, son malas- con otro, que estima el "valor absoluto de la elección en sî" $(1997, \text { p. } 73)^{1}$. En juego están no solo las consecuencias de la decisión sino la autonomía de la persona que la tomó. Dworkin concluye que la segunda línea de argumentación puede "permitir un alcance del paternalismo más amplio del que podría sospecharse” (ibíd.).

C. L. Ten propuso otra interpretación del ejemplo de la esclavitud voluntaria. "El argumento de Mill no es claro", porque defiende la libertad de contrato que "nos permite renunciar a una parte de nuestra libertad cuando asumimos obligaciones vinculantes"(1980, p.117). E1 acto de un individuo que se compromete libremente a ser el esclavo

${ }^{1}$ Archard (1990) presenta una variante del argumento: el antipaternalismo consistente que no debe amparar acciones que tienden a autolimitar (selfabrogate) el ejercicio de la libertad del agente. De ahí que el contrato hipotético de Mill pueda prohibirse, sin que esto vulnere el compromiso con la defensa de la libertad. 
de otra persona es un tipo de contrato. Empero, este contrato particular es distinto de cualquier otro, dado que es irrevocable y porque, para el esclavo voluntario, elimina la posibilidad futura de cualquier decisión de cambio de status, es decir, de regresar a la condición de libertad. Ese contrato hace que ya no sea persona ante la ley. Según Ten, el problema sería distinto si el término de la servidumbre fuera limitado y si el esclavo voluntario tuviera periódicamente la opción de recuperar su libertad perdida.

Aunque el individuo seguiría renunciando a su libertad, el contrato no sería radicalmente diferente de otros contratos que limitan la libertad [...] El argumento que he propuesto en desarrollo del de Mill no prohíbe que una persona se convierta voluntariamente en esclava vitalicia de otra persona. Pero apoya el rechazo al reconocimiento legal de contratos cuyo objeto es la esclavitud perpetua (ibíd., p. 119).

La interpretación de Ten admite este caso de paternalismo por las muy especiales circunstancias que involucra. En otras palabras, la gente tiene derecho a equivocarse pero no a renunciar a la posibilidad de corregir sus errores ${ }^{2}$.

Richard Arneson aceptó que Mill era antipaternalista y afirmó: "Los argumentos de Mill, aunque sean exitosos en sus propios términos, pueden ser criticados desde la perspectiva de la justicia" (Arneson, 1997, p. 83), porque la libertad es peligrosa y no todas las personas tienen iguales condiciones para ejercerla. La libertad (entendida como la ausencia de paternalismo) tiene efectos diferenciados sobre personas distintas. Para las más capaces, la libertad puede tener todos los efectos positivos que Mill le atribuye. Para las menos capaces existe el riesgo de que las deje "peor de lo que estarían de otra forma" (ibíd., p. 87). Aun si suponemos que las ganancias de los más capaces superan las pérdidas de los menos capaces, Arneson juzga inaceptable que los segundos deban asumir los costos de una sociedad no paternalista.

Una posición extrema en este debate es la de James Fitzjames Stephen en su crítica temprana a Sobre la libertad. Para él, la defensa de la libertad de Mill es sencillamente inmoral. En sus palabras:

El principal asunto del que se ocupa la ley son los derechos y deberes, y los derechos y deberes más comunes e importantes presuponen una teoría de la moral [...] Tal vez la mejor ilustración del carácter moral del derecho civil se halla en las leyes relacionadas con el matrimonio y la

2 Frederick (2014) conjetura que algunos individuos pueden ser "esclavos naturales", en el sentido de que esa condición favorece o incluso es necesaria para su realización como personas. Pero llega a la misma conclusión de Ten: la esclavitud voluntaria solo es permisible cuando es temporal. 
herencia. Todas parten de una teoría esencialmente moral sobre las relaciones entre los géneros (Stephen, 1997, pp. 172-173).

\section{ESCLAVITUD Y PATERNALISMO EN MILL}

Un aspecto curioso del debate sobre el paternalismo de Mill a la luz del ejemplo de la esclavitud voluntaria es la escasa discusión de sus puntos de vista muy explícitos sobre uno y otro tema.

A mediados del siglo xIx muchos opinaban que los males del capitalismo y del surgimiento del mercado no regulado como principal institución social podrían remediarse volviendo a un pasado hipotético: un orden social más armónico, humano y jerárquico, dentro del cual las clases sociales estaban ligadas por vínculos de respeto, obediencia y protección. En este escenario, los ricos velan por el bienestar material y espiritual de los pobres. Lo que se pretendía, en esencia, era un paternalismo benevolente.

En 1845 Mill publicó una ácida reseña de un libro representativo de ese género de conservatismo social progresista, The claims of labour de Arthur Helps. El fin buscado por ese autor era una situación donde la ley obligaría a los pudientes a asegurar el sustento de los pobres, independientemente de que su trabajo pudiera emplearse con provecho. Mill citó dos ejemplos de ese modelo: la servidumbre en Rusia y la esclavitud en las Indias Occidentales. Al respecto escribió:

La relación que se pretende establecer entre las clases terrateniente y manufacturera y los trabajadores no carece de ejemplos. Las primeras sí han sido obligadas a mantener a los segundos, y a ofrecerles trabajo, o a mantenerlos cuando están ociosos. Pero esta obligación nunca ha existido, ni nunca existirá ni podrá existir, sin el elemento compensatorio de poder absoluto (o algo parecido) de aquellos que ofrecen el sostenimiento sobre aquellos que tienen el derecho de recibirlo [...] [E1] cuidado paternal está asociado a la autoridad paternal (CW, IV, p. 374).

Mill desarrolló el mismo argumento en los Principios de economía política. El punto de partida de su discusión del futuro de la clase trabajadora (descrita por Lionel Robbins como una de las "formulaciones más destacadas sobre los principios fundamentales del liberalismo clásico”, CW, IV, XXVI) es el contraste entre lo que Mill denominó

la teoría de la dependencia y la protección y [la teoría de la] la autodependencia. Según la primera teoría el destino de los pobres, en todo lo que les afecta colectivamente, debería regularse para ellos y no por ellos [...] La relación entre ricos y pobres, según esa teoría (que también se aplica a la relación entre hombres y mujeres) debería ser solo parcialmente autoritaria (CW, III, p. 759). 
Mill expuso varias razones para apartarse de la teoría paternalista de la dependencia. La idea de que las relaciones entre pobres y ricos serían solo "parcialmente autoritarias" le pareció una idealización sin sustento, así como la noción de que la autoridad siempre se ejercería con benevolencia. "Todas las clases privilegiadas y poderosas, como tales, han usado su poder en el interés de su propio egoísmo" (ibíd., p. 760) ${ }^{3}$. Luego aplicó la misma crítica en el contexto de la familia:

Los llamados protectores son hoy los únicos respecto de quienes, en circunstancias ordinarias, se requiere protección. La brutalidad y la tiranía que llenan los registros policiales son las de los maridos contra las esposas, las de los padres contra los hijos (ibíd., p. 761).

Argumentos adicionales se desprenden de la perspectiva de los beneficiarios putativos del paternalismo económico y social. Para Mill, la naturaleza de la clase trabajadora se había transformado: los obreros se habían acostumbrado a leer la prensa y discutir la política entre sí, y habían perdido su sentido de inferioridad ante la clase alta. Habían progresado en inteligencia y autonomía. El paternalismo, sin que importe cuán bien intencionado fuese, se haría cada vez más intolerable para ellos. Mill se anticipa aquí a un tema central de Sobre la libertad. E1 futuro de la clase trabajadora depende de que sus vidas se regulen no para ellos sino por ellos mismos.

Mill fue enemigo vitalicio de la esclavitud. Cuando hizo su mejor esfuerzo para analizar objetivamente la economía positiva de esa peculiar institución en los Principios, concluyó sus comentarios calificándola como "enormidad" y afirmando que "no hay más que decir de una causa tan completamente juzgada y decidida" (CW, II, p. 250). La correspondencia privada de Mill está llena de referencias a sus opiniones abolicionistas ${ }^{4}$. Estas fueron la base de su polémica con Thomas Carlyle acerca de la "cuestión negra", en la cual Mill atacó los intentos de los antiguos esclavistas en los dominios británicos de perpetuar la servidumbre por otros medios después de la emancipación (1850). En su Autobiografía valoró su agitación contra la Confederación esclavista durante la Guerra Civil americana como uno de los

${ }^{3}$ Los Principios de Mill se editaron en 1848, el mismo año en que se publicó el Manifiesto del Partido Comunista de Marx y Engels.

${ }^{4}$ Cuando supo que el presidente Lincoln se aprestaba a proclamar la abolición, Mill escribió a John Lothrop Motley: “ningún americano, creo, habrá recibido esta noticia con la exaltación que me causó” (CW, XV, p. 800). A Joseph Henry Allen le manifestó que la abolición era "no solo la limpieza de una tacha sino de un íncubo moral que probablemente sea el inicio de un progreso moral no inferior a la prodigiosa expansión material que a futuro se fechará desde la aniquilación de la esclavitud negra” (CW, XVI, p. 974). 
principales logros de su vida pública. En sus propias palabras, fue un deber cumplido.

Cuando criticó la esclavitud, Mill tenía en mente dos formas de la institución: la que prevaleció en la Antigüedad y la que existía en su propio tiempo ${ }^{5}$. Ambas tenían las características esenciales descritas por R. M. Hare: "la esclavitud es, primero, un status social, y segundo, una relación con un amo" (1979, p. 105). Pero había algunas diferencias entre las dos.

La esclavitud de la Antigüedad era dura, pero tenía algunas características moderadoras. Las principales fuentes de esclavos eran la conquista, la piratería y el nacimiento de madre esclava. Sin embargo, la esclavitud podría ser la consecuencia de personas vendiéndose a sí mismas (el ejemplo de Mill), de la venta de hijos por padres insolventes o de penas legales. Podía haber algún grado de identidad cultural y ética entre los esclavos y sus amos. Un escritor antiguo, un pseudoAristóteles, recomendó a los amos evitar demasiada familiaridad con sus esclavos ${ }^{6}$. Según el derecho romano, la patria potestad del paterfamilias sobre su esposa e hijos no era muy diferente de su autoridad sobre sus esclavos. El significado inicial del término "emancipación" era el reconocimiento formal de que un hijo había llegado a la mayoría de edad y que quedaba libre de la patria potestad. Los amos griegos y romanos con frecuencia manumitían a sus esclavos, y los libertos en Roma podían acceder con facilidad a la ciudadanía. La institución de la esclavitud antigua tuvo un largo ocaso y fue gradualmente reemplazada por la servidumbre de la gleba.

La esclavitud moderna tenía una naturaleza distinta y fue consecuencia del descubrimiento de América. Después del colapso demográfico de la población indígena causado por la Conquista, muchos factores llevaron a la importación de africanos (capturados con violencia) para suplir las necesidades de mano de obra servil del hemisferio occidental. La esclavitud moderna desapareció paulatinamente durante la vida de Mill. En el Imperio británico se prohibió el tráfico transatlántico de esclavos en 1807, y la esclavitud como tal en 1838. Fue necesaria la Guerra Civil para poner fin a la esclavitud en Estados Unidos en 1863.

Si bien las condiciones de salida de las esclavitudes moderna y antigua eran similares (la manumisión), las condiciones de entrada eran distintas. Cualquier miembro de una sociedad de la Antigüedad, en

${ }^{5}$ Mill las menciona ambas en el capítulo 5 del segundo libro de los Principios.

${ }^{6}$ Las comedias de Aristófanes, Plauto y Terencio sugieren la frecuente cercanía personal entre amos y esclavos.

Revista de Economía Institucional, vol. 2 i, n. ${ }^{\circ} 40$, Enero-junio/20i9, Pp. i63-i 83 ISSN OI 24-5996/E-ISSN 2346-2450 
principio, podía convertirse en esclavo en determinadas circunstancias. La esclavitud moderna afligía a un grupo específico: los negros. Las únicas formas de encontrarse en la condición de esclavo eran haber sido secuestrado en África o haber nacido de una esclava negra.

E1 punto clave es que la esclavitud moderna estaba fundamentada en una distinción racial. Era por lo demás impensable e ilegal en la época de Mill que una persona libre se vendiera como esclava ${ }^{7}$. Usar un ejemplo tan extremo para explicar los límites de la libertad individual podría considerarse una suerte de disquisición sobre el sexo de los ángeles con pocas, si es que alguna, implicaciones sobre cuándo es admisible el paternalismo.

La plausible lectura que hace Ten del problema de la esclavitud voluntaria distingue entre la servidumbre vitalicia y otras formas de obligaciones que solo limitan de manera temporal la libertad. Empero, una forma de servidumbre temporal que sí existió en la época de Mill fue la del trabajo "coolie" o culí. Trabajadores chinos o indios se contrataban para trabajar en países lejanos durante un plazo limitado. Al final del término acordado podían regresar a su patria o volverse colonos libres en el sitio de destino. Mill desaprobó esta forma de servidumbre temporal. En una carta de 1871 a Henry George sobre la migración china a Estados Unidos se opuso a la limitación de la misma: sus efectos negativos para ese país serían mínimos, mientras que habría efectos positivos derivados del contacto de los migrantes con la sociedad y los valores norteamericanos. Con una salvedad: "Hay un tipo de medida restrictiva que me parece no solo deseable sino indispensable: leyes muy estrictas contra la introducción de chinos como culíes, es decir bajo contratos que les impongan el servicio a personas particulares" (CW, XVII, pp. 1654-1655).

¿El ejemplo de la esclavitud voluntaria era meramente hipotético? A continuación se examinarán los conceptos de Mill sobre los derechos de propiedad como una creación social cuyo alcance puede ser limitado en interés de la sociedad, y del matrimonio y el divorcio como relevantes por su analogía con el problema de la esclavitud voluntaria.

\section{LOS LÍMITES DE LOS DERECHOS DE PROPIEDAD}

Mill pertenecía a la tradición utilitaria, en la cual los derechos de propiedad son una construcción social. Bentham, por ejemplo, sostuvo que la propiedad era la mera expectativa de utilidad derivada de la

7 De hecho, aun en la Antigüedad era infrecuente. Ver la discusión de Scheidel (2007).

Revista de Economía Institucional, vol. 2 i, N. ${ }^{\circ}$ 40, enero-junio/20i9, pp. i63-i 83 ISSN OI 24-5996/E-ISSN 2346-2450 
posesión de una $\operatorname{cosa}^{8}$. Para Mill, la base de los derechos de propiedad es su utilidad social, y se pueden limitar por cualquier disposición derivada del "consentimiento de la sociedad" (CW, II, p. 200). E1 elemento esencial de la propiedad privada es "el reconocimiento [de la sociedad] a cada quien del derecho exclusivo a disponer lo que él o ella haya producido con su propio esfuerzo o haya recibido por donación o por acuerdo justo, sin uso de fuerza o fraude, de quien lo haya producido" (ibíd., p. 215).

Dicho eso, hay varios tipos de propiedad individual para los cuales cabían excepciones a esa regla general. Dos de los más notables son la tenencia de tierra y la herencia. A diferencia de las mejoras, la tierra no es fruto de la actividad humana. "Cuando en cualquier país el propietario, en términos generales, no cumple la función de hacer mejoras, la economía política no hace defensa alguna de la propiedad privada de la tierra que allí prevalece" (ibíd., p. 228). Mill usó este argumento para justificar la reforma agraria. Mill no ponía en duda el derecho de legar; todos tienen la libertad de disponer de su riqueza. Afirmaba, sin embargo, que el derecho a heredar más allá de ciertas cuantías razonables no era acorde con la conveniencia social $^{9}$. Finalmente, estaba la esclavitud. Para Mill esta pertenecía a la categoría respecto de la cual "ningún derecho de propiedad debería existir" (ibíd., p. 232).

En sociedades con economías de mercado, la mayoría de los derechos de propiedad se originan en contratos. Otro aspecto de la discusión es el papel del gobierno en su regulación y en su capacidad de asegurar su cumplimiento. Este es tanto un asunto de orden práctico como de principios. La hipótesis del estado de naturaleza de Hobbes enseña que la intervención pública (por medio de códigos y juzgados) es necesaria para los intercambios normales entre individuos, a la vez que limita la libertad de estos.

En el ejemplo de Sobre la libertad citado al principio de este artículo, Mill afirma que "un compromiso mediante el cual una persona se vende o permite que sea vendida como esclava sería nulo e inválido; y no sería susceptible de hacerse cumplir por la ley ni por la opinión pública”. Independientemente de las cuestiones morales suscitadas por la decisión del esclavo arrepentido de incumplir sus obligaciones contractuales, es la validez legal de tal contrato lo que le daría a su

${ }^{8}$ Ver la discusión del apéndice del capítulo IV de Cooter y Ulen (2002).

9 En ambos casos, el reconocimiento social de derechos propiedad -cuya creación no guardaba relación con la actividad productiva del dueño- era, en opinión de Mill, un incentivo inconveniente. 
amo el derecho de solicitar a la autoridad pública que lo capture y devuelva, usando la fuerza de ser necesario.

En los Principios, Mill analiza el alcance y la naturaleza de las funciones generales del gobierno. Estas incluyen hacer cumplir los contratos, lo cual es un medio para hacer efectiva la voluntad expresa de las partes contratantes (CW, III, p. 801). Pero, ¿implica esto que todo contrato debe hacerse cumplir? En una prefiguración del ejemplo posterior de Sobre la libertad, Mill afirma:

E1 interés público no es compatible con que las personas tengan el poder de comprometerse mediante ciertos tipos de promesas. Sin hablar de compromisos de hacer cosas prohibidas por la ley, hay obligaciones que la ley se niega a hacer cumplir, por razones relacionadas con el interés del obligado o con la política general del Estado. Un contrato por medio del cual una persona se vende como esclava a otra sería declarado nulo e ineficaz por los tribunales de este país y los de la mayoría de las naciones europeas (ibíd., p. 802).

Se introduce una nueva consideración: el "interés público" o la "política general del Estado”. Debe anotarse que la política pública no es necesariamente paternalista en el sentido de la definición de Dworkin. Puede involucrar un genuino conflicto entre los intereses público y privado, que legitima al Estado para intervenir en conductas que no solo afectan el actor.

¿Cuál puede ser el interés público en prohibir la esclavitud voluntaria? El capítulo final de los Principios se ocupa de los límites del "dejad-hacer", en otras palabras, de las razones por las que el Estado debe intervenir en asuntos sociales y económicos. Una interpretación posible de la posición de Mill es que justifica la acción estatal como respuesta a lo que hoy se denominan fallas del mercado ${ }^{10}$. Una de estas es la externalidad de decisión: cuando una persona toma decisiones que determinan el bienestar de otra. Si la primera recibe los beneficios mientras que la segunda asume los costos, la elección no necesariamente maximizará su utilidad conjunta y puede ser injusta en términos distributivos. No se trata de que

el gobierno intervenga en la dirección de sus propios intereses y conducta de los individuos, sino de si debería dejar enteramente en su poder los intereses y conducta de otra persona [...] Cuando resulta claro qué deberían hacer, o dejar de hacer, los padres respecto de sus hijos, la ley está justificada e incluso obligada a prescribir o proscribir las conductas respectivas. Para poner un ejemplo del ámbito de la economía política: es correcto que los niños y jóvenes sean protegidos del trabajo excesivo, en la medida en que el Estado lo pueda hacer. Trabajar horarios dema-

${ }^{10}$ Ver la discusión de Pérez Salazar (2003, cap. VII). 
siado largos, o hacer labores superiores a su fuerza, no debería permitírseles, porque si se lo hace se abre la puerta a la compulsión. La libertad de contrato, en el caso de menores, equivale a la libertad de coerción (CW, III, p. 952).

Mill hace una advertencia similar sobre contratos que implican obligaciones irrevocables, perpetuas o de muy larga duración. Esta categoría incluye la esclavitud voluntaria. Cuando se pacta este tipo de contrato, el que acepta ser esclavo nunca puede disponer de información suficiente sobre las consecuencias que este puede tener para su bienestar en circunstancias cambiantes e imprevisibles ${ }^{11}$. Sin importar cuán racional sea el actor, no puede tomar decisiones racionales bajo condiciones de incertidumbre ${ }^{12}$. Es un caso extremo de información imperfecta. Mill lo generaliza así:

La regla general de libertad de contratación no se aplica sin gran dificultad a obligaciones perpetuas; la ley debería ser muy celosa respecto de tales obligaciones y no aprobarlas cuando las obligaciones impuestas son tales que la parte contratante no puede ser juez competente de ellas; y si alguna vez las sanciona, debería tomar todas las precauciones para que el consentimiento sea informado y deliberado; y en compensación por no permitir a las partes revocar sus compromisos por su cuenta, debería permitir que esa revocatoria sea hecha por autoridad competente cuando haya razones que la justifiquen (ibíd., p. 954).

Sin embargo, Mill no usa la esclavitud voluntaria para ilustrar su argumento; acude al "matrimonio, el más importante de todos los casos de compromiso vitalicio".

\section{MATRIMONIO, DIVORCIO Y LA CONDICIÓN DE LA MUJER}

La analogía entre la esclavitud y la condición de la mujer era fácil para Mill ${ }^{13}$. Para citar apenas un ejemplo, afirmó que la democracia

${ }^{11}$ Entre ellas, la interpretación discrecional del contrato por el amo en el futuro. La relación entre la persona que se vende como esclavo y el comprador tiene una asimetría adicional. La primera no puede decidir, de manera unilateral, volver a la libertad, mientras que el amo siempre puede poner fin al contrato con la manumisión.

${ }^{12}$ En el sentido de no tener información sobre eventos futuros, en contraste con el riesgo (en que se tiene al menos alguna información sobre la probabilidad de eventos futuros). Esta distinción fue propuesta por Frank Knight (1921).

${ }^{13}$ La analogía no era original. Offen (2001) la traza desde las integrantes del grupo de las Précieuses del siglo XVII, como Madeleine de Scúdery. Esta tradición continuó en el siglo XVIII con Montesquieu y Rousseau y tuvo un papel importante en la redefinición del derecho civil durante la Revolución francesa, antes de la reacción napoleónica que se incorporó en el Código Civil. 
en Estados Unidos tenía el lunar de que la "aristocracia de la piel y la aristocracia del género retienen sus privilegios" (CW, XVIII, p. 55, nota $)^{14}$. E1 desarrollo de esta analogía en El sometimiento de la mujer, con especial referencia al matrimonio y al divorcio, lleva a concluir que su posición sobre la esclavitud voluntaria es antipaternalista. Como lo es la premisa básica del libro.

En asuntos prácticos la carga de la prueba debe recaer sobre quienes se oponen a la libertad; quienes proponen cualquier restricción, prohibición o limitación de la libertad general de la acción humana, o cualquier descalificación o disparidad de privilegio que afecte a una persona o a una categoría de personas con relación a otras $(1869$, p. 10).

La analogía se examinará desde tres perspectivas: las condiciones de ingreso al matrimonio, las condiciones de esta relación según la descripción de Mill y las condiciones de salida (separación o divorcio).

Para efectos de esta discusión se supone que la condición de ingreso -la decisión de la mujer de casarse- es voluntaria. Hay consentimiento pleno y consciente de su parte ${ }^{15}$. ¿En qué sentido es libre esa decisión? La respuesta de Mill incluye dos argumentos. Primero, la discriminación general contra la mujer limita su acceso a la educación y al trabajo bien remunerado. A menos que goce de condiciones excepcionales (p. ej., un patrimonio sustancial) tiene pocas posibilidades de sostenimiento material fuera del matrimonio. Segundo, la poca educación que se imparte a las mujeres impone un sistema de valores que incluye la convicción de que son inferiores a los varones y que el matrimonio es su destino natural, indispensable para su realización personal. Como señaló en una carta a Auguste Comte: “jamás un grupo de esclavos fue tan cuidadosamente educado, desde la primera infancia, en la firme creencia de que debe estar siempre sometido a otros hombres" (CW, XIII, p. 609) ${ }^{16}$. E1 adoctrinamiento sistemático de un grupo (social o sexual) desfavorecido para que crea que la sujeción le conviene tiene mucho de paternalismo, pero esta variedad de paternalismo no se podría atribuir a Mill.

\footnotetext{
${ }^{14}$ Se trata de su reseña del libro de Tocqueville. Los términos "esclavo" y "esclavitud" se usan setenta veces en El sometimiento de la mujer. No es coincidencia que la primera traducción al castellano (de Agustín Avrial) tuviera el título La esclavitud de la mujer (1892, Madrid).

${ }^{15}$ Por supuesto, una mujer puede ser coaccionada a casarse, como una persona a someterse a la esclavitud. Pero en tal caso la analogía con la esclavitud voluntaria deja de ser aplicable.

${ }^{16}$ Los puntos de vista de Comte sobre la igualdad de género eran menos progresistas que los de Mill.
}

Revista de Economía Institucional, vol. 2 i, n. ${ }^{\circ} 40$, Enero-junio/20i9, Pp. i63-i 83 ISSN OI $24-5996 / \mathrm{E}-$ ISSN 2346-2450 
Sus argumentos no suponen, sin embargo, que estemos ante lo que Joel Feinberg (1971) denominó decisiones "sustancialmente involuntarias”, que harían caer a Mill en la categoría del paternalismo fuerte ${ }^{17}$. Mill no niega que la decisión de una mujer de contraer matrimonio puede ser fiel reflejo de sus valores y preferencias autónomas.

Para la mujer, las condiciones del matrimonio implican dos rasgos esenciales de la definición de Hare de la esclavitud: un status social que conlleva la privación de ciertos derechos y una relación subordinada con un amo (1979, p. 105). Mill describió la condición de la mujer casada como la de una "esclava no forzada sino voluntaria" (1869, p. 16). En la Inglaterra de Mill, el derecho de familia disponía que el marido absorbía

completamente todos los derechos, toda la propiedad y toda la libertad de acción [de su esposa]. Los dos son considerados "una persona en derecho", para efectos de inferir que todo lo de ella es de él, pero nunca se hizo la inferencia paralela de que lo que es de él sea de ella. La regla no se aplica contra el varón, salvo al hacerlo responsable de las acciones de la esposa contra terceros, como lo es un amo de los actos de sus esclavos o de su ganado [...] ¿Cuál es la posición de la esposa respecto de los hijos, en los que tiene un interés conjunto? Por ley, los hijos son del marido. Solo él tiene derechos legales sobre ellos (ibíd., p. 27) ${ }^{18}$.

El matrimonio en esas condiciones rebajaba el status de la mujer y la subordinaba al varón. Era un contrato que creaba y regulaba derechos de propiedad, según el cual como regla general todos los bienes de la casada pertenecían al esposo. Tenía él muchos de los derechos que los amos tenían sobre sus esclavos; la gran excepción era la imposibilidad de que la mujer casada fuera vendida.

La subordinación de la esposa a su marido con frecuencia se justificaba con argumentos afines a la defensa aristotélica de la esclavitud: puesto que las mujeres naturalmente son inferiores a los hombres, entonces su subordinación a ellos las favorece. La crítica de Mill tenía como base la pregunta del cui bono: ¿quién se beneficia? La desigualdad impuesta beneficia a unos a costa de otros. La posición de quienes sostenían que el lugar apropiado de la mujer era el trabajo doméstico y el cuidado de los niños podría expresarse así: es socialmente necesario

17 Según Feinberg, la decisión sería sustancialmente voluntaria si, y solo si, quien toma la decisión es competente; la decisión no es constreñida; la decisión no es fruto de manipulación más sutil (como, p. ej., sugestión posthipnótica); el que decide no lo hace por ignorancia o por creencias equivocadas sobre las consecuencias de sus actos ni está sujeto a condiciones que distorsionan transitoriamente su juicio.

${ }_{18}$ Para una discusión más amplia de la institución británica del matrimonio en la época de Mill, ver Shanley (1981).

Revista de Economía Institucional, vol. 2 i, N. ${ }^{\circ}$ 40, enero-junio/20i9, Pp. i63-i 83 ISSN OI 24-5996/E-ISSN 2346-2450 
que las mujeres se casen y se reproduzcan. Y no lo harán a menos que se les obligue. Por tanto, es necesario obligarlas. Una opinión paralela era la de los esclavistas del sur de Estados Unidos: "Es necesario que se cultive algodón y caña de azúcar. Los blancos no pueden hacerlo. Los negros no quieren, por el sueldo que estamos dispuestos a pagarles. Ergo, deben ser obligados" (Mill, 1869, p. 25). Este paternalismo no es altruista ni benévolo, aunque trate de disfrazarse como si lo fuera. Es apenas un pretexto para el ejercicio de la explotación.

Mill afirmaba que la estructura asimétrica del matrimonio tendría efectos negativos incluso para los varones a los que favorece. La dominación corrompe el carácter tanto del esclavo como del amo, tanto de la esposa como del marido (cuando las condiciones del matrimonio son desiguales). "El poder casi ilimitado que las instituciones sociales actuales dan al varón sobre al menos un ser humano [...] busca y evoca los gérmenes latentes del egoísmo en los lugares más recónditos de su naturaleza $[y]$ le permite ser indulgente con aquellos elementos de su carácter íntimo que en cualquier otra relación se sentiría obligado a reprimir" (ibíd., p. 31).

Las condiciones de salida del matrimonio son la separación y el divorcio. En el caso del esclavo voluntario, puede darse un cambio de parecer sobre la conveniencia de la decisión inicial de someterse. Pero, a menos que el amo conceda la emancipación, su única alternativa es la fuga. Ahora bien, la institución de la esclavitud supone que la autoridad pública hará su mejor esfuerzo para capturarlo y devolverlo a su amo. Un esclavo que opta por la libertad es un delincuente; dispone del bien de otro (su propia persona) sin el consentimiento del dueño. Mill subrayó este aspecto de la analogía entre esclavitud y matrimonio (para las mujeres) en estos términos: "Si [la mujer] deja su esposo, no puede llevar nada consigo, ni sus hijos ni lo que es justamente suyo. Si él así elige, puede obligarla a volver, por medios legales o por el uso de la fuerza física; o puede apropiarse para sí todo lo que ella gane con su trabajo o lo que reciba de sus parientes" (ibíd., p. 28) ${ }^{19}$.

En El sometimiento de la mujer, Mill señaló que la separación legal no era una opción viable salvo para una pequeña minoría de mujeres pudientes; no abordó una discusión detallada del divorcio, que era aún más difícil para ellas.

En otros escritos, Mill hizo algunas consideraciones explícitas sobre el segundo tema. El más temprano fue un ensayo privado dirigido a Harriet Taylor, probablemente en 1832. E1 contexto biográfico es

${ }^{19}$ La situación de los varones respecto de la separación y el divorcio era bien distinta.

Revista de Economía Institucional, vol. 2 i, N. ${ }^{\circ}$ 40, enero-junio/20i9, Pp. I63-i 83 ISSN OI $24-5996 / \mathrm{E}-\mathrm{ISSN} 2346-245^{\circ}$ 
importante. Mill había conocido a la señora Taylor (casada con otro) el año anterior y se habían enamorado. Según Hayek, la señora Taylor obtuvo permiso de su marido para una separación experimental de seis meses en 1833 (Hayek, 1951, p. 45). Este ensayo probablemente fue parte del intento de Mill para persuadirla a divorciarse, con alguna expectativa de lograrlo ${ }^{20}$.

Nadie puede negar que hay muchos casos en los que la felicidad de ambas partes sería promovida por la disolución del matrimonio [...] Entonces, los argumentos en favor de la indisolubilidad del matrimonio no son nada en comparación con los argumentos más poderosos en favor de dejar que esta, como otras relaciones acordadas por seres humanos, dependa de su continuación de los deseos de las partes contratantes (Mill, 1832, pp. 69-74) ${ }^{21}$.

Mill retornó a este asunto en dos obras posteriores: en la parte final de los Principios y en el capítulo conclusivo de Sobre la libertad. En esta última menciona los intereses de terceros: los hijos habidos en el matrimonio que sería disuelto por divorcio ${ }^{22}$ :

Si la relación entre dos partes contratantes ha tenido consecuencias para terceros; si $[\ldots]$ en el caso del matrimonio ha generado la existencia de esos terceros $[\ldots]$ una persona debe tener en cuenta todas estas circunstancias antes de tomar una decisión que puede afectar intereses tan importantes de otros; y si no sopesa adecuadamente esos intereses tiene responsabilidad moral por el daño. He hecho estos comentarios obvios para una mejor ilustración del principio general de libertad y no porque todos se requieran en el análisis de esta cuestión en particular; por el contrario, a veces se discute como si el interés de los niños fuera todo y el de los adultos nada (CW, XVIII, pp. 300-301) ${ }^{23}$.

${ }^{20}$ De hecho, la señora Taylor decidió seguir casada con su primer esposo hasta que él falleció en 1849. Dos años después se casó con Mill.

${ }^{21}$ Según Mill, dos razones válidas para el divorcio eran la "no congenialidad de disposiciones" y "una fuerte pasión de una de las partes hacia una tercera persona”.

${ }^{22}$ El ensayo de 1832 también tocó este tema. La señora Taylor tenía varias hijas de su primer marido.

${ }^{23}$ Estas palabras siguen el ejemplo del esclavo voluntario. La transición entre uno y otro tema se hace así: "Sin embargo, el principio que exige libertad de acción sin restricciones para todo lo que concierne solo a los agentes exige que quienes se han vinculado entre sí en asuntos que no conciernen a terceros, deberían poder liberar el uno al otro de su compromiso; y aun sin esa renuncia voluntaria quizá no haya contratos o compromisos, excepto los monetarios, en los cuales uno podría atreverse a decir que no hay libertad de retractación” (ibíd.). 


\section{CONCLUSIONES}

La tesis defendida en este artículo es que si bien el hipotético caso de la esclavitud voluntaria guarda relación con el esclavismo al que tanto se opuso Mill, así como con su concepción de los derechos de propiedad, su preocupación central es la naturaleza profundamente desigual del matrimonio en la Inglaterra victoriana.

La analogía entre la esclavitud voluntaria y el matrimonio ayuda a entender por qué Mill moduló con tanto cuidado su "caso extremo". Mill no dijo que a las personas debería prohibírseles venderse a sí mismas como esclavas; dijo que tal compromiso sería "nulo e inválido; y no sería susceptible de hacerse cumplir por la ley ni por la opinión pública", y que el hecho de que aquel les causara daño "sería razón suficiente para liberarl[a]s de esa obligación” (CW, XVIII, p. 299). Mill no desaprobaba el matrimonio. De hecho, buena parte de $E l$ sometimiento de la mujer se dedica al elogio de lo que puede llegar a ser esa institución en condiciones óptimas ${ }^{24}$.

Es posible que el debate sobre el paternalismo de Mill haya girado en torno a la pregunta equivocada. Lo que estaba en juego en su ejemplo no era si prohibir que la gente se vendiera como esclava se debería considerar una restricción de la libertad individual. Más bien indagaba si la sociedad debería hacer cumplir los derechos de propiedad derivados de ese tipo de contrato.

Si la analogía entre el matrimonio y la esclavitud voluntaria es válida, la discusión de Mill sobre la primera institución en su época sugiere que esta era causa y consecuencia de restricciones de la libertad individual de la mitad de la raza humana. Las mujeres se casaban a pesar del sometimiento que implicaba ese estado, porque tenían muy pocas posibilidades de escoger otro proyecto de vida. Una educación sesgada las inclinaba al matrimonio. Una vez casadas, quedaban en condiciones de desigualdad legal aguda. Y la posibilidad de recuperar su libertad, si esa desigualdad tenía consecuencias negativas para ellas, era muy restringida, tanto por motivos de derecho vigente como por las sanciones sociales contra las mujeres que buscaban el divorcio ${ }^{25}$.

${ }^{24} \mathrm{Su}$ unión con Harriet Taylor fue, a todas luces, muy feliz.

${ }^{25}$ Es probable que una razón por la que Harriet Taylor no se divorció de su primer marido en 1833 fue la desaprobación que ello hubiera generado en su círculo social. La amistad de la señora Taylor con J. S. Mill y su posterior matrimonio provocaron la censura de muchos de sus amigos y aun de la familia de Mill. De allí la doble condición: "no susceptible de hacerse cumplir por la ley ni por la opinión” (resaltado nuestro). 
Sobre el supuesto paternalismo de Mill pueden formularse varias conclusiones. La aseveración de Dworkin de que el ejemplo de Mill considera "el valor absoluto de la elección en sî" es perfectamente váli$\mathrm{da}^{26}$. Es este el tema central del tercer capítulo de Sobre la libertad. Pero su inferencia de que esto puede "permitir un alcance del paternalismo más amplio de lo que podría sospecharse" sobrepasa el significado y la intención de Mill. Si su discusión sobre el matrimonio es pertinente para la solución del problema de la esclavitud voluntaria, esta tiene varios elementos que no caben dentro de la definición de paternalismo de Dworkin. Entre ellos, las externalidades negativas para terceros (el conflicto entre la decisión individual del esclavo voluntario y los intereses generales de la sociedad ${ }^{27}$ ) y el hecho de que la sociedad no está obligada a hacer cumplir todo derecho de propiedad surgido de un contrato privado, aun si el objeto del contrato no es en sí ilegal ${ }^{28}$.

De hecho la posición de Mill podría entenderse como un rechazo del paternalismo fuerte (porque no interfiere con la intención de quien se vende como esclavo o de la mujer que se casa en condiciones de aguda desigualdad), sin llegar a ser paternalismo suave. No es que se impida la elección del agente de entrar en un contrato irrevocable, pero ni el Estado ni la sociedad están obligados a hacer cumplir ese contrato en caso de que una de las partes cambiare de parecer.

La diferencia entre servidumbre permanente y servidumbre temporal aducida por Ten también es un argumento válido pero insuficiente. Mill quizá no hubiera estado de acuerdo con la interpretación que realiza Ten de su punto de vista, dado que hace caso omiso de las externalidades negativas creadas por el trabajo servil en una economía donde la regla es la libertad individual. Hacer cumplir contratos de trabajo culí -o cualquier otra forma de servidumbrecrearía distorsiones en el mercado laboral, con problemas tanto de ineficiencia como de injusticia. Más ampliamente, cualquier forma de esclavitud es inconsistente con el interés público de una sociedad libre. De nuevo, el cargo de paternalismo contra Mill no cumple la definición de Dworkin por cuanto involucra terceras partes.

${ }^{26}$ Fuchs (2001) elabora un argumento afín, donde el valor pertinente es la autonomía personal.

27 Mill creía que la restricción de la libertad de la mujer dentro del matrimonio probablemente llevaba a que tuvieran más hijos de los que tendrían en condiciones menos desiguales; desde la perspectiva de su economía política ricardiana, el excesivo crecimiento demográfico se consideraba la causa fundamental de la pobreza. Ver la discusión de Pérez S. (2003, pp. 105-107).

${ }_{28}$ Así, los juegos de azar pueden ser legales pero las deudas de juego no ser susceptibles de cobro legal.

Revista de Economía Institucional, vol. 2 i, n. ${ }^{\circ} 40$, Enero-junio/20i9, Pp. i63-i 83 ISSN OI 24-5996/E-ISSN 2346-2450 
Para James Fitzjames Stephen, "el carácter moral del derecho civil se halla en las leyes relacionadas con el matrimonio y la herencia. Todas parten de una teoría esencialmente moral sobre las relaciones entre los géneros" (1997, p. ). Dada esta premisa, el paternalismo no es problemático. La "teoría moral" de Stephen es la inferioridad inherente de las mujeres respecto de los varones. Para Mill, la cuestión de la igualdad de capacidades de los géneros no era "moral" sino empírica. A su juicio, las mujeres nunca habían tenido la oportunidad de demostrar su igualdad. La experiencia del siglo xx le dio la razón a Mill. En el ámbito de la literatura, una de las mejores pruebas de su tesis fue la obra de la la hija de Leslie Stephen (hermano de James Fitzjames), Virginia Woolf.

Uno de los aspectos más interesantes del debate es el reparo de Arneson al antipaternalismo de Mill con base en el criterio de equidad. Darle a la gente la libertad de experimentar con sus vidas, de cometer sus propios errores, dañará de manera desproporcionada a quienes son más propensos a cometerlos. Mill era consciente del problema y lo mencionó de manera explícita en su discusión del paternalismo en los Principios. A diferencia de Arneson, tuvo en cuenta que el paternalista puede (o más probablemente tendrá) motivos ulteriores y egoístas. E1 paternalismo degenera fácilmente en "libertad de coerción".

Mill usó un argumento más fundamental: la gente aprende de sus errores, como creía que hacía la clase trabajadora inglesa de su época. Si no se le permite elegir, no aprenderá. El aprendizaje hace que los "menos capaces" (en el lenguaje de Arneson) mejoren sus capacidades y con ello la calidad de sus decisiones. Mejora también sus cualidades como seres humanos. A diferencia de Arneson, que supone que los menos capaces seguirán siéndolo, Mill sostuvo que, a la larga, hombres y mujeres, como los seres progresivos que son, se beneficiarán del antipaternalismo a medida que estrechen la brecha entre los más y los menos capaces. El antipaternalismo es por ello más equitativo que el paternalismo. La línea de pensamiento de Mill es afín al énfasis de Amartya Sen en la libertad y la agencia individual como algo esencial para el desarrollo ${ }^{29}$.

Harriet Taylor Mill expuso un argumento similar en un ensayo de 1852, "Enfrachisement of women":

${ }^{29}$ Para Sen, un agente es "alguien que actúa y provoca cambios y cuyos logros se pueden juzgar en términos de sus propios valores y objetivos, independientemente de que también los valoremos en términos de otros criterios externos" (1999, p. 19). 
La agitación que ha comenzado no es un ruego de escritores y oradores masculinos en favor de las mujeres, siendo estas presuntas beneficiarias indiferentes o incluso hostiles; [...] es un movimiento no solo para las mujeres sino por las mujeres.

La diferencia entre para y por es la esencia del antipaternalismo de Mill y su esposa. Esta distinción también se halla en los Principios y tuvo eco en la definición de la democracia hecha por Lincoln en su alocución de Gettysburg, pocos años después: una forma de gobierno que no es solo "del pueblo" y "para el pueblo", sino "por el pueblo".

¿Fue Mill un antipaternalista consistente? Evidentemente exceptuó el caso de personas que no están en condiciones de razonar. Es este el sentido primigenio de "paternalismo", y su defensa de la educación universal obligatoria es claramente paternalista. Un aspecto más inquietante, desde la perspectiva de nuestro tiempo, es otra analogía propuesta por Mill entre la inmadurez de los individuos y la de ciertos pueblos no "civilizados", que usó para justificar el colonialismo en el capítulo final de su Gobierno representativo (CW, XIX) ${ }^{30}$.

\section{REFERENCIAS BIBLIOGRÁFICAS}

Archard, D. (1990). Freedom not to be free: The case of the slavery contract in J.S. Mill's On liberty. Philosophical Quarterly, 4O(161), 453-465.

Arneson, R. J. (1980). Mill versus paternalism. Ethics, 90(4), 470-489.

Arneson, R. J. (1997). Paternalism, utility and fairness. En G. Dworkin, ed., Mill's On liberty: Critical essays (pp. 83-114). Lanham: Rowman $\&$ Littlefield.

Cooter, R. y Ulen, T. (2002). Derecho y economia. México DF: Fondo de Cultura Económica.

Dworkin, G. (1997). Paternalism. En G. Dworkin, ed. Mill's On liberty: Critical essays (pp. 61-82). Lanham: Rowman \& Littlefield.

Dworkin, G. (2017). Paternalism. The Stanford Encyclopedia of Philosophy [https://plato.stanford.edu/entries/paternalism/].

Feinberg, J. (1971). Legal paternalism. Canadian Journal of Philosophy, $1(1), 105-124$.

Frederick, D. (2014). Voluntary slavery. Las Torres de Lucca, 4, 115-137.

Fuchs, A.G. (2001). Autonomy, slavery and Mill's critique of paternalism. Ethical Theory and Moral Practice, 4(3), 231-251.

Hamburger, J. (1999). Mill on liberty and control. Princeton: Princeton University Press.

Hare, R. M. (1979). What is wrong with slavery. Philosophy and Public Affairs, 8(2), 103-121.

Hayek, F. A. (1951). John Stuart Mill and Harriet Taylor: Their friendship and subsequent marriage. London: Routledge \& Kegan Paul.

Knight, F. (1921). Risk, uncertainty and profit. Boston: Houghton Mifflin.

30 Para una discusión más amplia con base en la dicotomía civilizaciónbarbarie, ver Moloney (2011). 
Mill, H. T. (1852). Enfranchisement of women. En John M. Robson (ed.), The Collected Works of John Stuart Mill, XXI (pp. 393-416) .Toronto: University of Toronto Press.

Mill, J. S. (1832). Essay on marriage and divorce. En F. A. Hayek, John Stuart Mill and Harriet Taylor: Their friendship and subsequent marriage. Londres: Routledge \& Kegan Paul.

Mill, J. S. (1850). The negro question. Littell's Living Age version, 465-469.

Mill, J. S. (1869). The subjection of women. Nueva York: D. Appleton and Company.

Mill, J. S. (varios). Las demás referencias citadas en el texto provienen de John M. Robson, ed. (1963-1991). The Collected Works of John Stuart Mill. Toronto: University of Toronto Press.

Moloney, P. (2011). John Stuart Mill on savagery, slavery and civilization, [https://papers.ssrn.com/sol3/papers.cfm?abstract_id=1976870].

Offen, K. (2001).How (and why) the analogy of marriage with slavery provided the springboard for women's rights demands in France. Proceedings of the Third Gilman Lehrman Center International Conference at Yale University (pp. 1-16). New Haven: Yale University.

Pérez S., M. (2003). La razón liberal: economía, politica y ética en la obra de John Stuart Mill. Bogotá: Universidad Externado de Colombia.

Scheidel, W. (2007). The Roman slave supply. Princeton: Stanford working papers in classics.

Shanley, M. L. (1981). Marital slavery and friendship: John Stuart Mill's The subjection of women. Political Theory, 9(2), 229-247.

Sen, A. (1999). Development as freedom. Nueva York: Knopf.

Stephen, J. F. (1997). The doctrine of liberty in its application to morals. En G. Dworkin, ed., Mill's On liberty: Critical essays (167-178). Lanham: Rowman \& Littlefield.

Ten, C. L. (1980). Mill on liberty, Oxford, Clarendon Press. 